OPEN ACCESS

Edited by:

Bilian Jin,

Dalian Medical University, China

Reviewed by:

Bo Peng,

Sun Yat-Sen University, China Jianxiang Shi,

Zhengzhou University, China

${ }^{*}$ Correspondence:

Zhiping Guo

hlohljt@163.com

${ }^{t}$ These authors have contributed equally to this work

Specialty section:

This article was submitted to

Cancer Immunity and Immunotherapy,

a section of the journal

Frontiers in Immunology

Received: 07 February 2021 Accepted: 08 April 2021

Published: 30 April 2021

Citation:

Li J, Qin B, Huang M,

Ma Y, Li D, Li W and Guo Z

(2021) Tumor-Associated Antigens

(TAAs) for the Serological

Diagnosis of Osteosarcoma.

Front. Immunol. 12:665106. doi: 10.3389/fimmu.2021.665106

\section{Tumor-Associated Antigens (TAAs) for the Serological Diagnosis of Osteosarcoma}

\author{
Jitian $\mathrm{Li}^{1+}$, Bo Qin ${ }^{2 \dagger}$, Manyu Huang ${ }^{1}$, Yan $\mathrm{Ma}^{1}$, Dongsheng $\mathrm{Li}^{1}$, Wuyin $\mathrm{Li}^{1}$ \\ and Zhiping Guo ${ }^{1 *}$
}

\begin{abstract}
1 Henan Luoyang Orthopedic Hospital (Henan Provincial Orthopedic Hospital)/Henan Institute of Orthopedic and Traumatology, Luoyang, China, ${ }^{2}$ Transitional Medical Center, The First Affiliated Hospital of Zhengzhou University, Zhengzhou, China
\end{abstract}

Osteosarcoma (OS) is the most common form of malignant bone tumor found in childhood and adolescence. Although its incidence rate is low among cancers, the prognosis of OS is usually poor. Although some biomarkers, such as p53, have been identified in OS, the association between the biomarkers and clinical outcome is not well understood. Thus, it is necessary to establish a method to identify patients diagnosed with OS at an early stage. It is becoming obvious that anti-tumor-associated antigens (TAAs) autoantibodies (TAAbs) in sera could be used as serological biomarkers in the detection of many different types of cancers. This notion indicates that TAAbs are considered as immunological "sentinels" associated with tumorigenesis underlying molecular events. It provides new insights into the molecular and cellular biology of the differential diagnosis of cancers. What's more, it is reported that a customized TAA array could significantly increase the sensitivity/specificity. TAA arrays also have great application prospects in detecting cancer at an early stage, monitoring cancer progression, discovering new therapeutic targets, and designing personalized treatment. In this review, we provide an overview of the TAAs identified in OS as well as the possibility that TAAs and TAAbs system be used as biomarkers in the immunodiagnosis and prognosis of OS.

Keywords: osteosarcoma, tumor-associated antigen, autoantibodies, biomarker, immunodiagnosis, prognosis

\section{INTRODUCTION}

Osteosarcoma (OS) is characterized by the production of bone-like substances by malignant osteoblasts, which is the most common and highly malignant primary bone tumor that originates from primary osteoblasts (1). It is, like all other sarcomas, rare with an incidence rate of less than $1 \%$ of all cancers diagnosed (2). It is estimated by the American Cancer Society that approximately 800 new cases arise in the USA each year, and about 400 of them are children and teens. OS is the most common form of bone cancer in children and adolescents ageing from 10 to 20 years old (3). Although the incidence rate of OS is relatively low among all cancers, OS is highly malignant and can often be neglected on misidentification with benign lesions or trauma since the initial symptoms of the disease are commonly quite nonspecific and subtle. Furthermore, OS progresses aggressively. About $20 \%$ of the patients have metastases usually detected in the lung 
when initially diagnosed (4-7). OS is one of the most dangerous primary malignant tumors in childhood and adolescence, resulting in a high rate of amputation, disability, and death. At present, therapy for OS is still inadequate. The five-year survival rate is approximately $60 \%$ even after pre- and post-operative, neoadjuvant chemotherapy and excision of operable lesions (8). Moreover, tumor size and metastases presented at initial diagnosis always portend a worse outcome $(5,9)$. Thus, a critical need in the diagnosis and treatment of OS is to select an optimal array of sera biomarkers that can be used in clinic. These biomarkers could assist to detect tumors at an early stage with high specificity/sensitivity and limited invasiveness. This array could help to predict whether patients in need of treatment will develop aggressive tumors.

Over the last few decades, many studies demonstrated that these autologous cells developing into tumors contained tumorassociated-antigens. The abnormal exposure or presentation of these antigens recognized by the human immune system could further trigger autoantibodies, that have been termed tumorassociated autoantibodies (TAAbs), against these cellular antigens. This notion has come from evidence that TAAbs are immunological "sentinels" associated with tumorigenesis underlying molecular events (10-12). The content of TAAbs could increase in the very early stage during carcinogenesis (13). TAAbs are stable with high levels in patients' sera even though the level of the corresponding antigens is low (14) or even after removal of these antigens $(15,16)$. Such benefits of TAAbs have triggered a growing enthusiasm for applying these TAAbs as serological cancer biomarkers. Moreover, in recent years, increasing attention has been given in humoral immunity to TAAs in particular clinical fields, such as the possible use of TAAs and TAAbs systems as cancer biomarkers not only in detecting cancer at an early stage, but also to monitor cancer progression, discover new therapeutic targets, and design personalized therapeutic interventions (17).

At present, emerging studies engaged at the molecular markers or pathways on OS have revealed the key roles of these molecules (13) in OS tumorigenesis and prognosis. These molecular markers could potentially be used to predict the diagnostic accuracy or micrometastasis when diagnosed and when to treat with chemotherapy. Further, such pathways could also be possible targets for new chemotherapeutic agents in OS. The information of the TAAs of human OS is still inadequate. There are too many genes and corresponding protein products, like melanoma-associated antigen (MAGE) (18), HER2 (19), p53 (20), HSP (21), squamous cell carcinoma antigen recognized by $\mathrm{T}$ cells (SART1) (22), SART3 (23), or papillomavirus binding factor $(\mathrm{PBF})(24)$, which were reported to be expressed in OS. Unfortunately, it is generally recognized that they are still insufficient in the application of available clinical information in diagnosing cancer early, designing personalized treatment, and predicting prognosis. Therefore, it is necessary to develop innovative diagnostic and prognostic tools to effectively manage OS by utilizing clinical biomarkers.

This review aims to summarize the established and experimental TAAs and TAAbs tested in OS in recent years. It is useful to summarize the idea and possibility of detecting TAAs and TAAbs in the immunodiagnosis and prognosis of OS.

\section{TAAs IN OS}

It is now evident that the sera of cancer patients comprise autoantibodies that can react with TAAs. These TAAs are varied and contain a unique group of autologous cellular antigens $(10,25,26)$, including the tumor suppressor p53 (27, 28), oncogene products such as HER-2/neu and ras (29), proteins that protect mRNAs from degradation such as p62 (30) and CRD-BP (31), onconeural antigens (32), differentiation-antigens such as tyrosinase and the cancer/testis antigens (33), and antiapoptotic proteins such as survivin (34) and LEDGF (35). The factors leading to the production of these autoantibodies are not fully understood. The existing studies suggested that many target antigens were cellular proteins, and their abnormal regulation or overexpression may lead to tumorigenesis. This could take p53 for example $(27,28)$. In the case of mRNA binding protein $\mathrm{p} 62$, a fetal protein missing in adult tissues, immunogenicity seems to be associated with abnormal expression of p62 in cells of tumor (36). In some cancer patients, the immune system seems to have the ability to sense these abnormalities and react by producing autoantibodies (37). Autoantibodies associated with a particular type of cancer are targeted at proteins that are abnormally regulated or activated in the molecular pathways involved in the malignant transformation of that particular type of cancer (38). Taken together, TAAbs may be considered as the reporter of abnormal cellular mechanisms during tumorigenesis (10).

Although the reports on types and functions of TAAs in OS are still limited, these tumors might express some diagnostic and/ or therapeutic targets. The numerous TAAs summarized in Table 1 have been described in previous studies. In human OS, the high expression rate of HER2/erbB-2 was 40-45\%, which was related to poor prognosis, early lung metastases, and poor response to preoperative chemotherapy $(39,40)$. p53 was localized in euchromatic areas of nuclei of OS cells, and was involved in the development of OS, but not correlated with any clinical factors $(20,41)$. Some previous reports had shown that the expression of P-glycoprotein may have an association with the increasing risk of chemotherapy resistance $(42,43,76,77)$. Afterward, it was reported that hsp27 was overexpressed related to the poor prognosis of OS (44). Sudo et al. suggested that melanoma antigen (GAGE) family members were expressed in substantial numbers of OS as tumor-rejection antigens in the main histocompatibility class-I restriction mode (18). And in sarcoma cell lines, hsp72 was selectively expressed on the cell surface, overcoming the protective effect and acting as a target for natural killer cells (46), which was related to the good response of neoadjuvant chemotherapy (47). The GD2 ganglioside was found overexpressed in OS (48) and later, some groups demonstrated that the therapy anti-GD2 antibody can improve the survival rate of high-risk neuroblastoma (49). Two tumorrejection antigens, SART1 (22) and SART3 (23), were reported to be expressed in OS, which suggests that these proteins and their 
TABLE 1 | Identification of TAAs or TAAbs analyzed in multiple studies.

\begin{tabular}{ll}
\hline TAA or TAAb & Description \\
\hline HER2 & Oncogene \\
P53 & Tumor suppressor \\
P-glycoprotein & ATP-binding cassette (ABC) transporters
\end{tabular}

$\begin{array}{ll}\text { Hsp27 } & \text { Heat shock protein 27, protein chaperone and antioxidant } \\ \text { MAGEA } & \text { Melanoma antigen family A } \\ \text { Hsp72 } & \text { Heat shock protein } 70 \text { family and a chaperone protein } \\ \text { GD2 } & \begin{array}{l}\text { Disialoganglioside GD2, a sialic acid-containing } \\ \text { glycosphingolipid }\end{array} \\ \text { SART1, } & \begin{array}{l}\text { Squamous cell carcinoma antigen recognized by T cells, } \\ \text { SART3 }\end{array} \\ \text { B7-H3 } & 58 \text { kDa glycosylated tumor-associated protein antigen }\end{array}$

Melanoma MCAM (melanoma cell adhesion molecule) and as CD146 antigen

MUC18

CXCR4

SAA

CLUAP1

GAGE 1,2,8 NY-ESO-1

Survivin
Midkine
OSAA-3 and
OSAA-5
PBF

TEM1

IL-11R $\alpha$

FAP

Tim-3

PCNA

CEACAM6

ANG-IgM

CDK5

CEACAM1

EZH2

BMl-1

p16INK4A (endothelial antigen)

Chemokine receptor type 4, an alpha-chemokine receptor

Serum amyloid A, a family of apolipoproteins associated with high-density lipoprotein (HDL)

Clustering associated protein 1

g melanoma antigen (GAGE)

New York esophageal squamous cell carcinoma 1 (NY-ESO1), a cancer-testis antigen

Inhibitor of apoptosis

Heparin-binding growth factor

Unknown

Papillomavirus binding factor (PBF)

Tumor endothelial marker 1 (TEM1), prototypical member of a family of genes expressed in the stroma of tumors.

Interleukin-11 receptor alpha-chain

Fibroblast activation protein

T-cell immunoglobulin and mucin domain-3-containing molecule 3

proliferating cell nuclear antigen

Carcinoembryonic antigen-related cell adhesion molecule 6 angiogenin

Cyclin-dependent kinase 5

Carcinoembryonic antigen related cell adhesion molecule 1

Enhancer of zeste homologue 2

$\mathrm{B}$ cell-specific Moloney murine leukemia virus integration site 1

PRDX $2 \quad$ peroxiredoxin 2

CXCL4, CXC chemokines

CXCL6

Anti-hsp60

antibody

Anti-hsp90

antibody

Anti-MUC18

antibody

Anti-midkine
Autoantibodies against heat shock protein60

Autoantibodies against heat shock protein90

Autoantibody against MUC18

Autoantibody against midline
Observation in OS

Ref.

Correlates with poor prognosis for patients with OS.

$(39$,

Fails as a maker in OS because of no significant correlation between p53 expression and the clinical outcome and response to chemotherapy.

Increased risk for chemotherapy resistance.

Correlates with poor prognosis for patients with OS.

Expressed in substantial numbers of OS in a major histocompatibility class-Irestricted manner.

Correlates with a good response to neoadjuvant chemotherapy.

Overexpressed in OS.

Potentially used in specific immunotherapies HLA-A24 $4^{+}$patients with OS or malignant fibrous histiocytosis.

Potential molecules for use in specific immunotherapies for $\mathrm{HLA}-\mathrm{A} 24^{+}$patients with OS or malignant fibrous histiocytosis.

Correlates directly with tumor progression and metastatic potential.

$(44)$

$(18$,

45)

$(46$,

47)

$(48$,

49)

$(22$,

Potentially used as a prognostic factor and as a predictor of potential metastatic development in OS.

Increased SAA levels associated with type of tumor and high-risk OS

development.

Potentially used as a prognostic/diagnostic marker and/or for a target of immunotherapy of OS.

Expressed GAGE-1, 2, 8 in all 9 OS tissue samples.

(52)

(53)

(54)

Expressed NY-ESO-1 in 8 of 9 OS tissue samples.

(55)

Potentially used as an independent predictor of survival for OS patients. Correlates with the prognosis of patients with OS.

Potentially used as candidates for diagnosis and targets for immunotherapy in OS.

May contribute to peptide-based vaccination and/or adoptive antigen-specific T- (59) cell therapy of patients with OS and other bone and soft tissue tumors.

Potentially used as a target protein for selective therapeutic intervention.

(56)

(60)

May represent a new therapy for patients with OS pulmonary metastases.

Might be considered as a novel therapeutic target against this cancer. (62)

Potential diagnostic and prognostic biomarker for OS progression.

Inhibited OS cell proliferation

A potential therapeutic target for the treatment of metastatic OS

Serve as a biomarker for increased risk of OS

Pro-malignant role

May be a prognostic biomarker for OS

May be tumor-associated antigens of OS

May be tumor-associated antigens of OS

(64)

(66)

(67)

(68)

(69)

(69)

May be a useful biomarker to guide the treatment of OS.

$(70$,

A candidate for chemotherapy responsiveness marker in OS

Associated with OS patient outcomes

Increases of anti-hsp60 antibodies at the time of first diagnosis of OS.

Correlates with a good response to neoadjuvant chemotherapy and their absence (75) correlates with the occurrence of metastases.

Inhibits the development of OS metastases in a preclinical model.

(51)

Inhibits growth of OS cells in vitro.

(57) 
derived peptides could be used as specific immunotherapy molecules in OS patients with HLA-A24+ or malignant fibrous histiocytosis. It was the uniform expression of $\mathrm{B} 7-\mathrm{H} 3$ (8H9 antigen) on the cell membrane that makes it an attractive candidate for targeted immunotherapy (50). Additionally, a cell adhesion molecule, the human METCAM/MUC18 (melanoma antigen/MUC18), with a high expression level in OS played an important role in the metastasis of OS, suggesting that ABXMA1 might be a new immunotherapeutic approach for OS (51). Furthermore, the study also concluded that, by using a preclinical model, anti-MUC18 antibodies could inhibit the process of OS metastases (51). In the past few years, a relationship between the expression of CXCR4 and initial metastases was discovered (52). SAA expressed higher in OS than benign bone tumors and normal subjects (53). CLUAP1 as potentially a prognostic/diagnostic marker for OS (54) has been suggested. Jacobs et al. reported that all nine OS tissue samples expressed GAGE-1, 2, and 8, and eight of nine expressed NYESO-1, application of cancer-testis antigens or cancer germline genes expressed in solid tumor research of pediatrics (55). Like the other tumors, survivin was also overexpressed in OS as an anti-apoptotic molecule. Several investigators had revealed that the overexpression of survivin was associated with worse clinical outcome, which may be used as an independent predictor for OS patients in survival field (56). More recently, Maehara et al. showed that the expression level of midkine, a heparin-binding growth factor midkine, has an association with the prognosis of OS patients. Anti-midkine functional antibodies can effectively inhibit the growth of OS cells in vitro (57).

In the recent past, several studies have done their best to verify new targeting sites for immunotherapy exploiting neither humoral or cellular immune responses to OS, although their precise role in cell biology remains unclear. Among them, OSAA-3 and OSAA-5, two serological antigens, were identified exclusively in the sera of OS patients, but not in normal individuals, which suggests that these two antigens' immune responses were related to OS (58). Papillomavirus binding factor (PBF) was identified by derived cDNA library screening with autologous tumor-reactive CD8+T cells. PBF was overexpressed in most OS and might be helpful for peptidebased vaccine inoculation and/or adoptive antigen-specific Tcell therapy in OS patients as well as in other bone and soft tissue tumors (59). The report by Rouleau et al. showed that the measured level of endosialin/tumor endothelial marker 1 (TEM1) was low in normal tissues, but in several sarcoma subtypes it was in high levels, suggesting that TEM1 may work as a suitable target protein for selecting therapeutic intervention (60). In more recent years, researchers found that interleukin 11 receptor alpha $(\operatorname{IL} 11 \mathrm{R} \alpha)(61)$ and fibroblast activation protein (FAP) (62) were selectively expressed in OS patients compared with healthy groups, which suggests that they may play roles during the process of OS development and progression.

On the other hand, the recognition that the production of TAAbs was stimulated by human tumors has opened a new chapter in cancer biology. More and more studies began to focus on the possibility that autoantibodies may be used as serological tools to diagnose and manage cancer early (78). It has been reported that the titer of anti-hsp60 autoantibody was increased in OS patients but it was not found to be associated with clinical parameters (74). One year later, the other group reported that such immunoreactivity against hsp90 may have predictive value in OS patients because the presence of anti-hsp90 autoantibodies was associated with a good response to neoadjuvant chemotherapy, and their absence was associated with the occurrence of metastasis (75).

Upon the current limited information, TAAbs in OS seem to target proteins involved in tumorigenesis, with high expression in bone tumors. Unfortunately, many published studies on the identification of TAAs have failed to further detail this association. Additionally, since molecular diagnostic and/or prognostic markers have not been established clinically, risk stratification is mainly based on the initial stage of the illness and the reaction to chemotherapy. It would be essential to develop a new focus to identify diagnostic and prognostic indicators to detect these drug-resistant tumors as soon as possible so that more aggressive treatment can be used to improve the outcomes at the first stage of diseases.

\section{APPROACHES TO TAAs IDENTIFICATION}

In the past few decades, several approaches have been used to identify TAAs. The most successful methods are serological screening of cDNA expression libraries and phage display libraries, and the latest methods based on proteomics. Based on these techniques, putative TAAs with high-titer reactivity were identified in sera. Subsequently, TAAbs from these sera were used to isolate the antigen DNA sequence from the cDNA expression libraries. In this way, several new TAAs, including p62 (30) and p90 (79), were discovered in our studies. Afterward, several new and previously defined TAAs (25) were identified with cancer sera using a method called serological analysis of recombinant cDNA expression libraries (SEREX), which was an improvement of the method before (80). In cases of OS, it was the SEREX method that could identify new and previously defined TAAs, including CLUAP1 (54), OSAA-3, and OSAA5 (58).

With the development of proteomic technology in recent years, the field of bone cancer has entered the era of proteomic research, which aims to identify serum biomarkers using proteomics methods, to carry out early and non-invasive diagnosis of cancer, and monitor the progress of the tumor. By using two-dimensional gel electrophoresis (2-DE) system and mass spectroscopy, one method involved direct analysis of human cancer sera to identify specific protein characteristics of different tumor types $(6,81-84)$. Li et al. used SELDI-TOF-MS to analyze the patients' sera of OS and osteochondroma, which provided the first example for the identification and verification of the protein biomarker characteristics of OS and found a unique cluster of proteins in the data of patients with bone 
tumor, which were discrete SAA subtypes (53). A second approach was used in our research (Figure 1) and focused on developing a serum autoantibody library for cancer patients to identify TAAs, in order to better diagnose and manage OS by using customized TAA panels or arrays $(78,85)$. which was termed as serological proteome analysis (SERPA) (86). Compared with SEREX, the technology of the SERPA allows individuals to screen a large number of sera and to identify a large number of candidate TAAs in a shorter time. The proteomebased approach, commonly known as immunoproteomics (80), can also discriminate antigen subtypes and detect the presence of post-translational modified autoantibodies for specific targets. Moreover, this also sheds light on rapid progress in determining vaccine-associated protein antigens (87), immune-related substances, and biomarkers for disease diagnosis and prognosis (80). In recent years, this approach has been used by our lab to extensively screen sera of certain types of cancer patients such as hepatocellular carcinoma (HCC) (88), esophageal squamous cell carcinoma (ESCC) (89), as well as sera from patients with precancerous lesions such as liver fibrosis (90), to identify and

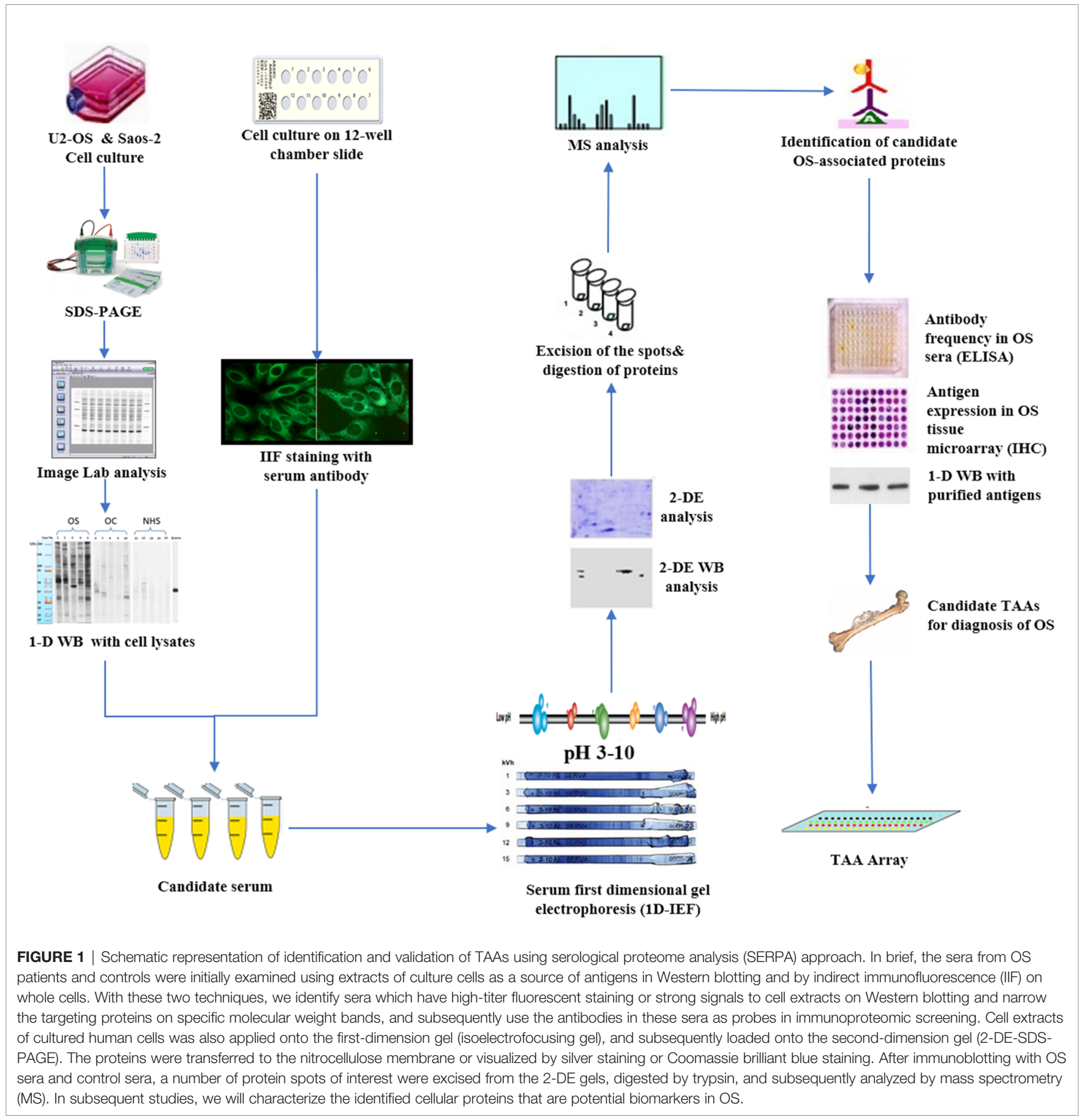


characterize the latent TAAs. To support the development and characterization of TAAs in our lab, this protocol was developed to screen the immune sera of patients. As shown in Figure 1, Western blotting and indirect immunofluorescence (IIF) were used to detect the sera from OS patients and corresponding healthy controls, initially examined by using proteins extracted from tissue culture cells as antigens source. By using these two techniques, the western blotting method identified sera with hightiter fluorescent staining or react with cell extracts on strong signals, then the antibodies were used in these sera as probes for immunoproteomic screening. After cultured human cell extract was applied onto the isoelectrofocusing gel (first-dimensional gel), it was subsequently loaded onto the (2D-SDS-PAGE). Right after the proteins transferred to the nitrocellulose membrane (NC membrane), silver staining or Coomassie brilliant blue staining was used to visualize the spots. Some protein spots were removed from 2D gels and digested with trypsin after immunoblotting with OS sera and control sera, then liquid chromatography-tandem mass spectrometry (LC-MS/MS) was used to do some analysis. In the following studies, a variety of methods, including EnzymeLinked Immunosorbent Assay (ELISA), 1D Western blotting, and immunohistochemistry (IHC) with tissue arrays, were used to comprehensively characterize and verify the candidate TAAs and TAAbs systems. In addition to the above methods, single molecule array (Simoa) is a new super sensitive detection technology based on the sandwich method of digital ELISA and combined with high-throughput array technology $(91,92)$. It has a sensitivity 1000 times higher than ordinary ELISA (93). It also has obvious advantages for the detection of low abundance protein markers, and the detection limit can be as low as fg/ml (94). These screening systems have potential application value in cancer immunodiagnosis. Afterwards, the sensitivity and specificity of different antigen-antibody systems as certain types of cancer markers was evaluated for "TAA arrays" systems developed for diagnosing, predicting cancer, and tracking responses of patients treated in the future.

\section{APPLICATION OF TAA-ARRAYS IN OS}

Interestingly, TAAbs used as serological markers for the further use of cancer diagnosis stems from the recognition that the expression level of these autoantibodies is usually absent or present in low levels in normal persons and non-cancer patients (85). Comparted with other tumor markers, they present persistence and stability circulation in the sera of cancer patients and may present before the development of cancer, giving them greater early diagnostic and/or prognostic potential (38). Compared with autoimmune diseases, the presence of a particular autoantibody may have diagnostic value; when evaluated individually TAAb has little diagnostic value. This is mainly because of their low frequency, sensitivity, and specificity. Such a limitation has been observed in our previous study and we found it would be optimized by using a properly selected TAA mini-arrays. Furthermore, different TAA arrays were used to diagnose different types of cancer to achieve the required sensitivity and specificity. This then makes immunodiagnosis a feasible auxiliary means to diagnosing tumors and even in predicting prognosis (26).

Our pioneering findings provided evidence that the ability of autoantibodies to detect cancers could be substantially improved by using a series of several TAAs, such as mini-arrays, as target antigens $(26,95,96)$. For instance, this mini-array comprised 14 full-length recombinant proteins expressed from cDNAs encoding survivin, CAPER $\alpha$, RalA, p62, Koc, MDM2, cyclinB1, p53, 14-3-3ל, p90, IMP1, c-Myc, NPM1, and p16. This mini-array was customized for the detection of hepatocellular carcinoma (HCC). The frequency of autoantibodies to any of these individual TAA was variable, ranging from $5.6 \%$ to $21.1 \%$ in HCC (97). Nevertheless, with the continuous addition of TAAs in the final 14 TAAs, the positive antibody response of HCC gradually increased to $69.7 \%$ in HCC (97). These data indicate that the combined application of multiple TAAs has a higher sensitivity in the serological diagnosis of cancer. More recently, we have evaluated 29 protein antigens identified in OS sera. It was found that only eight protein antigens - DSF70, HMGB1, HCC1, RalA, c-Myc, AnnexinA1, IMP1, and PBP - can induce significantly higher antibody responses in patients with OS with the highest sensitivity and specificity of 0.66 and 0.95 , respectively, compared with normal individuals (unpublished data). In a further study, using the panel of these eight TAAs contributes to a $70.7 \%$ increase in antibody-positive reactions with an observed AUC of 0.972 (95\% CI: 0.867-0.988). These preliminary data extensively supported that not all proteins identified in cancer can be used as be potential TAAs in OS immunodiagnosis or prognosis; only some of them can induce immune responses.

In addition to being potential biomarkers for the immunodiagnosis or prognosis of OS, TAA also has potential as a target for immunotherapy. Vaccinations including peptidebased vaccines are a promising active treatments as more and more TAAs become available for tumor immunotherapy, with the advantage of being easily produced and having minimal toxicity (98-101). For instance, MUC4 could be used as a candidate therapy for the treatment of pancreatic cancer (102). Studies conducted personalized TAA panels to treat patients with glioblastoma multiforme or advanced lung cancer (103). More effective vaccine regimes about TAAs, as well as the mechanism of action of vaccines, should be studied in the future.

\section{CONCLUSIONS}

In conclusion, a critical need in the diagnosis and management of OS is to identify a convincing combination of biomarkers used in clinic. These biomarkers could detect tumors at an early stage with limited invasiveness as well as high sensitivity/specificity, which could accurately predict which patients will develop aggressive tumors requiring treatment. Recent research on the TAAs and TAAbs provided a great promise in discovering new 
tumor biomarkers. The key to these TAAs or TAAbs is to illustrate a new understanding of the molecular mechanisms associated with the skeletal consequences of malignant tumors. There is growing evidence suggesting these tumors may express multiple diagnostic and/or therapeutic targets, although the information on the repertoire and function of TAA in OS is still limited. Our previous studies have provided strong evidence that enhance cancer detection and treatment; TAA arrays provide promising and powerful tools, even though the clinical application of TAA arrays is still in its infancy. It would be necessary to improve the sensitivity and specificity of TAA by identifying new TAAs and systematically defining the optimal combination of TAAs before TAA arrays could be widely used as tools in screening programs for cancer diagnosis or monitoring cancer progression and guiding therapeutic interventions. The results of these studies are greatly anticipated.

\section{REFERENCES}

1. Huvos AG. Ewing's Sarcoma. In: Bone tumors Diagnosis Treat prognosis Saunders Philadelphia (1991). 523-52.

2. Mirabello L, Troisi RJ, Savage SA. Osteosarcoma Incidence and Survival Rates From 1973 to 2004: Data From the Surveillance, Epidemiology, and End Results Program. Cancer (2009) 115(7):1531-43. doi: 10.1002/cncr.24121

3. Ward E, DeSantis C, Robbins A, Kohler B, Jemal A. Childhood and Adolescent Cancer Statistics, 2014. CA Cancer J Clin (2014) 64(2):83-103. doi: $10.3322 /$ caac.21219

4. de Santos LA, Edeiken BS. Subtle Early Osteosarcoma. Skeletal Radiol (1985) 13(1):44-8. doi: 10.1007/bf00349093

5. Rosenberg ZS, Lev S, Schmahmann S, Steiner GC, Beltran J, Present D. Osteosarcoma: Subtle, Rare, and Misleading Plain Film Features. AJR Am J Roentgenol (1995) 165(5):1209-14. doi: 10.2214/ajr.165.5.7572505

6. Gu J, Li J, Huang M, Zhang Z, Li D, Song G, et al. Identification of Osteosarcoma-Related Specific Proteins in Serum Samples Using SurfaceEnhanced Laser Desorption/Ionization-Time-of-Flight Mass Spectrometry. J Immunol Res (2014) 2014:649075. doi: 10.1155/2014/649075

7. Kaste SC, Pratt CB, Cain AM, Jones-Wallace DJ, Rao BN. Metastases Detected At the Time of Diagnosis of Primary Pediatric Extremity Osteosarcoma At Diagnosis. Cancer (1999) 86(8):1602-8. doi: 10.1002/ (SICI)1097-0142(19991015)86:8<1602::AID-CNCR31>3.0.CO;2-R

8. Ta HT, Dass CR, Choong PF, Dunstan DE. Osteosarcoma Treatment: State of the Art. Cancer Metastasis Rev (2009) 28(1-2):247-63. doi: 10.1007/ s10555-009-9186-7

9. Trieb K, Kotz R. Proteins Expressed in Osteosarcoma and Serum Levels as Prognostic Factors. Int J Biochem Cell B (2001) 33(1):11-7. doi: 10.1016/ S1357-2725(00)00066-2

10. Tan EM. Autoantibodies as Reporters Identifying Aberrant Cellular Mechanisms in Tumorigenesis. J Clin Invest (2001) 108(10):1411-5. doi: 10.1172/jci14451

11. Cheever MA, Allison JP, Ferris AS, Finn OJ, Hastings BM, Hecht TT, et al. The Prioritization of Cancer Antigens: A National Cancer Institute Pilot Project for the Acceleration of Translational Research. Clin Cancer Res (2009) 15(17):5323-37. doi: 10.1158/1078-0432.CCR-09-0737

12. Restifo NP, Dudley ME, Rosenberg SA. Adoptive Immunotherapy for Cancer: Harnessing the T Cell Response. Nat Rev Immunol (2012) 12 (4):269-81. doi: 10.1038/nri3191

13. Zayakin P, Ancāns G, Siliņa K, Meistere I, Kalniņa Z, Andrejeva D, et al. Tumor-Associated Autoantibody Signature for the Early Detection of Gastric Cancer. Int J Cancer (2013) 132(1):137-47. doi: 10.1002/ijc.27667

14. Lu H, Goodell V, Disis ML. Humoral Immunity Directed Against TumorAssociated Antigens as Potential Biomarkers for the Early Diagnosis of Cancer. J Proteome Res (2008) 7(4):1388-94. doi: 10.1021/pr700818f

15. Pedersen JW, Wandall HH. Autoantibodies as Biomarkers in Cancer. Lab Med (2011) 42(10):623-8. doi: 10.1309/LM2T3OU3RZRTHKSN

\section{AUTHOR CONTRIBUTIONS}

ZG and WL conceived the study. JL and BQ drafted the application sections; they contributed equally to this work. MH, YM, and DL revised and approved the final manuscript. All authors contributed to the article and approved the submitted version.

\section{FUNDING}

This work was supported by the National Natural Science Foundation of China (82004397), the Major Project of TCM research in Henan Province (2018ZYZD01 and 20-21ZYZD12), the Major Project of Science and Technology in Henan Province (212102310152), and the Project of Health Guiding Plan in Luoyang (1930005A).

16. Anderson KS, Cramer DW, Sibani S, Wallstrom G, Wong J, Park J, et al. Autoantibody Signature for the Serologic Detection of Ovarian Cancer. J Proteome Res (2014) 14(1):578-86. doi: 10.1021/pr500908n

17. Disis M, Montgomery R, Goodell V, de la Rosa C, Salazar L. Antibody Immunity to Cancer-Associated Proteins. Am Assoc Cancer Res Educ Book (2005) 2005:166-69.

18. Sudo T, Kuramoto T, Komiya S, Inoue A, Itoh K. Expression of MAGE Genes in Osteosarcoma. J Orthop Res (1997) 15(1):128-32. doi: 10.1002/jor.1100150119

19. Hudziak RM, Schlessinger J, Ullrich A. Increased Expression of the Putative Growth Factor Receptor P185her2 Causes Transformation and Tumorigenesis of NIH 3T3 Cells. Proc Natl Acad Sci USA (1987) 84 (20):7159-63. doi: 10.1073/pnas.84.20.7159

20. Ueda Y, Dockhorn-Dworniczak B, Blasius S, Mellin W, Wuisman P, Bocker W, et al. Analysis of Mutant P53 Protein in Osteosarcomas and Other Malignant and Benign Lesions of Bone. J Cancer Res Clin Oncol (1993) 119 (3):172-8. doi: 10.1007/BF01229533

21. Trieb K, Lang S, Kotz R. Heat-Shock Protein 72 in Human Osteosarcoma: TLymphocyte Reactivity and Cytotoxicity. Pediatr Hematol Oncol (2000) 17 (5):355-64. doi: 10.1080/08880010050034283

22. Ishida H, Komiya S, Inoue $Y$, Yutani S, Inoue A, Itoh K. Expression of the SART1 Tumor-Rejection Antigen in Human Osteosarcomas. Int J Oncol (2000) 17(1):29-32. doi: 10.3892/ijo.17.1.29

23. Tsuda N, Murayama K, Ishida H, Matsunaga K, Komiya S, Itoh K, et al. Expression of a Newly Defined Tumor-Rejection Antigen SART3 in Musculoskeletal Tumors and Induction of HLA Class I-Restricted Cytotoxic T Lymphocytes by SART3-Derived Peptides. J Orthopaed Res (2001) 19(3):346-51. doi: 10.1016/S0736-0266(00)90031-7

24. Tsukahara T, Nabeta Y, Kawaguchi S, Ikeda H, Sato Y, Shimozawa K, et al. Identification of Human Autologous Cytotoxic T-Lymphocyte-Defined Osteosarcoma Gene That Encodes a Transcriptional Regulator, Papillomavirus Binding Factor. Cancer Res (2004) 64(15):5442-8. doi: 10.1158/0008-5472.Can-04-0522

25. Old LJ, Chen YT. New Paths in Human Cancer Serology. J Exp Med (1998) 187(8):1163-7. doi: 10.1084/jem.187.8.1163

26. Zhang JY, Megliorino R, Peng XX, Tan EM, Chen Y, Chan EK. Antibody Detection Using Tumor-Associated Antigen Mini-Array in Immunodiagnosing Human Hepatocellular Carcinoma. J Hepatol (2007) 46(1):107-14. doi: 10.1016/j.jhep.2006.08.010

27. Soussi T. P53 Antibodies in the Sera of Patients With Various Types of Cancer: A Review. Cancer Res (2000) 60(7):1777-88.

28. Crawford LV, Pim DC, Bulbrook RD. Detection of Antibodies Against the Cellular Protein P53 in Sera From Patients With Breast Cancer. Int J Cancer (1982) 30(4):403-8. doi: 10.1002/ijc.2910300404

29. Disis ML, Pupa SM, Gralow JR, Dittadi R, Menard S, Cheever MA. HighTiter HER-2/Neu Protein-Specific Antibody Can Be Detected in Patients With Early-Stage Breast Cancer. J Clin Oncol (1997) 15(11):3363-7. doi: $10.1200 /$ jco.1997.15.11.3363 
30. Zhang JY, Chan EK, Peng XX, Tan EM. A Novel Cytoplasmic Protein With RNA-Binding Motifs is an Autoantigen in Human Hepatocellular Carcinoma. J Exp Med (1999) 189(7):1101-10. doi: 10.1084/jem.189.7.1101

31. Doyle GA, Bourdeau-Heller JM, Coulthard S, Meisner LF, Ross J. Amplification in Human Breast Cancer of a Gene Encoding a C-Myc Mrna-Binding Protein. Cancer Res (2000) 60(11):2756-9.

32. Keene JD. Why is Hu Where? Shuttling of Early-Response-Gene Messenger RNA Subsets. Proc Natl Acad Sci USA (1999) 96(1):5-7. doi: 10.1073/ pnas.96.1.5

33. Stockert E, Jäger E, Chen YT, Scanlan MJ, Gout I, Karbach J, et al. A Survey of the Humoral Immune Response of Cancer Patients to a Panel of Human Tumor Antigens. J Exp Med (1998) 187(8):1349-54. doi: 10.1084/jem.187.8.1349

34. Ambrosini G, Adida C, Altieri DC. A Novel Anti-Apoptosis Gene, Survivin, Expressed in Cancer and Lymphoma. Nat Med (1997) 3(8):917-21. doi: $10.1038 / \mathrm{nm} 0897-917$

35. Daniels T, Zhang J, Gutierrez I, Elliot ML, Yamada B, Heeb MJ, et al. Antinuclear Autoantibodies in Prostate Cancer: Immunity to LEDGF/P75, a Survival Protein Highly Expressed in Prostate Tumors and Cleaved During Apoptosis. Prostate (2005) 62(1):14-26. doi: 10.1002/pros.20112

36. Lu M, Nakamura RM, Dent ED, Zhang JY, Nielsen FC, Christiansen J, et al. Aberrant Expression of Fetal RNA-Binding Protein P62 in Liver Cancer and Liver Cirrhosis. Am J Pathol (2001) 159(3):945-53. doi: 10.1016/s0002-9440(10)61770-1

37. Liu W, Peng B, Lu Y, Xu W, Qian W, Zhang J-Y. Autoantibodies to TumorAssociated Antigens as Biomarkers in Cancer Immunodiagnosis. Autoimmun Rev (2011) 10(6):331-5. doi: 10.1016/j.autrev.2010.12.002

38. Anderson KS, LaBaer J. The Sentinel Within: Exploiting the Immune System for Cancer Biomarkers. J Proteome Res (2005) 4(4):1123-33. doi: 10.1021/ pr0500814

39. Onda M, Matsuda S, Higaki S, Iijima T, Fukushima J, Yokokura A, et al. Erbb-2 Expression is Correlated With Poor Prognosis for Patients With Osteosarcoma. Cancer (1996) 77(1):71-8. doi: 10.1002/(sici)1097-0142 (19960101) 77:1<71::Aid-cncr13>3.0.Co;2-5

40. Gorlick R, Huvos AG, Heller G, Aledo A, Beardsley GP, Healey JH, et al. Expression of HER2/Erbb-2 Correlates With Survival in Osteosarcoma. J Clin Oncol (1999) 17(9):2781-8. doi: 10.1200/jco.1999.17.9.2781

41. Miller CW, Aslo A, Won A, Tan M, Lampkin B, Koeffler HP. Alterations of the P53, Rb and MDM2 Genes in Osteosarcoma. J Cancer Res Clin Oncol (1996) 122(9):559-65. doi: 10.1007/bf01213553

42. Serra M, Maurici D, Scotlandi K, Barbanti-Brodano G, Manara MC, Benini S, et al. Relationship Between P-Glycoprotein Expression and P53 Status in HighGrade Osteosarcoma. Int J Oncol (1999) 14(2):301-7. doi: 10.3892/ijo.14.2.301

43. Baldini N, Scotlandi K, Barbanti-Bròdano G, Manara MC, Maurici D, Bacci G, et al. Expression of P-Glycoprotein in High-Grade Osteosarcomas in Relation to Clinical Outcome. N Engl J Med (1995) 333(21):1380-5. doi: 10.1056/nejm199511233332103

44. Uozaki H, Horiuchi H, Ishida T, Imamura T, Machinami R. Overexpression of Resistance-Related Proteins (Metallothioneins, Glutathione-S-Transferase Pi, Heat Shock Protein 27, and Lung Resistance-Related Protein) in Osteosarcoma - Relationship With Poor Prognosis. Cancer (1997) 79(12):2336-44. doi: 10.1002/ (Sici) 1097-0142(19970615)79:12<2336::Aid-Cncr7>3.0.Co;2-J

45. Zou C, Shen J, Tang Q, Yang Z, Yin J, Li Z, et al. Cancer-Testis Antigens Expressed in Osteosarcoma Identified by Gene Microarray Correlate With a Poor Patient Prognosis. Cancer (2012) 118(7):1845-55. doi: 10.1002/cncr.26486

46. Multhoff G, Botzler C, Jennen L, Schmidt J, Ellwart J, Issels R. Heat Shock Protein 72 on Tumor Cells: A Recognition Structure for Natural Killer Cells. J Immunol (1997) 158(9):4341-50.

47. Trieb K, Lechleitner T, Lang S, Windhager R, Kotz R, Dirnhofer S. Heat Shock Protein 72 Expression in Osteosarcomas Correlates With Good Response to Neoadjuvant Chemotherapy. Hum Pathol (1998) 29 (10):1050-5. doi: 10.1016/s0046-8177(98)90412-9

48. Yu AL, Uttenreuther-Fischer MM, Huang CS, Tsui CC, Gillies SD, Reisfeld RA, et al. Phase I Trial of a Human-Mouse Chimeric Anti-Disialoganglioside Monoclonal Antibody Ch14.18 in Patients With Refractory Neuroblastoma and Osteosarcoma. J Clin Oncol (1998) 16(6):2169-80. doi: 10.1200/jco.1998.16.6.2169

49. Yu AL, Gilman AL, Ozkaynak MF, London WB, Kreissman SG, Chen HX, et al. Anti-GD2 Antibody With GM-CSF, Interleukin-2, and Isotretinoin for Neuroblastoma. N Engl J Med (2010) 363(14):1324-34. doi: 10.1056/ NEJMoa0911123
50. Modak S, Kramer K, Gultekin SH, Guo HF, Cheung NK. Monoclonal Antibody 8H9 Targets a Novel Cell Surface Antigen Expressed by a Wide Spectrum of Human Solid Tumors. Cancer Res (2001) 61(10):4048-54.

51. McGary EC, Heimberger A, Mills L, Weber K, Thomas GW, Shtivelband M, et al. A Fully Human Antimelanoma Cellular Adhesion Molecule/MUC18 Antibody Inhibits Spontaneous Pulmonary Metastasis of Osteosarcoma Cells in Vivo. Clin Cancer Res (2003) 9(17):6560-6.

52. Laverdiere C, Hoang BH, Yang R, Sowers R, Qin J, Meyers PA, et al. Messenger RNA Expression Levels of CXCR4 Correlate With Metastatic Behavior and Outcome in Patients With Osteosarcoma. Clin Cancer Res (2005) 11(7):2561-7. doi: 10.1158/1078-0432.Ccr-04-1089

53. Li Y, Dang TA, Shen J, Perlaky L, Hicks J, Murray J, et al. Identification of a Plasma Proteomic Signature to Distinguish Pediatric Osteosarcoma From Benign Osteochondroma. Proteomics (2006) 6(11):3426-35. doi: 10.1002/ pmic.200500472

54. Ishikura $\mathrm{H}$, Ikeda $\mathrm{H}$, Abe $\mathrm{H}$, Ohkuri $\mathrm{T}$, Hiraga $\mathrm{H}$, Isu $\mathrm{K}$, et al. Identification of CLUAP1 as a Human Osteosarcoma Tumor-Associated Antigen Recognized by the Humoral Immune System. Int J Oncol (2007) 30(2):461-7.

55. Jacobs JFM, Brasseur F, Hulsbergen-van de Kaa CA, van de Rakt MWMM, Figdor CG, Adema GJ, et al. Cancer-Germline Gene Expression in Pediatric Solid Tumors Using Quantitative Real-Time PCR. Int J Cancer (2007) 120 (1):67-74. doi: 10.1002/ijc. 22118

56. Osaka E, Suzuki T, Osaka S, Yoshida Y, Sugita H, Asami S, et al. Survivin Expression Levels as Independent Predictors of Survival for Osteosarcoma Patients. J Orthop Res (2007) 25(1):116-21. doi: 10.1002/jor.20291

57. Maehara H, Kaname T, Yanagi K, Hanzawa H, Owan I, Kinjou T, et al. Midkine as a Novel Target for Antibody Therapy in Osteosarcoma. Autoimmun Rev (2007) 358(3):757-62. doi: 10.1016/j.bbrc.2007.04.183

58. Liao B, Ma B, Liu Z, Zhang H, Long H, Yang T, et al. Serological Identification and Bioinformatics Analysis of Immunogenic Antigens in Osteosarcoma. Cancer Biol Ther (2007) 6(11):1805-9. doi: 10.4161/cbt.6.11.4868

59. Tsukahara T, Kawaguchi S, Torigoe T, Kimura S, Murase M, Ichimiya S, et al. Prognostic Impact and Immunogenicity of a Novel Osteosarcoma Antigen, Papillomavirus Binding Factor, in Patients With Osteosarcoma. Cancer Sci (2008) 99(2):368-75. doi: 10.1111/j.1349-7006.2008.00695.x

60. Rouleau C, Curiel M, Weber W, Smale R, Kurtzberg L, Mascarello J, et al. Endosialin Protein Expression and Therapeutic Target Potential in Human Solid Tumors: Sarcoma Versus Carcinoma. Clin Cancer Res (2008) 14 (22):7223-36. doi: 10.1158/1078-0432.Ccr-08-0499

61. Huang GX, Yu L, Cooper LJN, Hollomon M, Huls H, Kleinerman ES. Genetically Modified T Cells Targeting Interleukin-11 Receptor AlphaChain Kill Human Osteosarcoma Cells and Induce the Regression of Established Osteosarcoma Lung Metastases. Cancer Res (2012) 72(1):27181. doi: 10.1158/0008-5472.CAN-11-2778

62. Yuan D, Liu B, Liu K, Zhu G, Dai Z, Xie Y. Overexpression of Fibroblast Activation Protein and Its Clinical Implications in Patients With Osteosarcoma. J Surg Oncol (2013) 108(3):157-62. doi: 10.1002/jso.23368

63. Liu H, Zhi L, Duan N, Su P. Abnormal Expression of Tim-3 Antigen on Peripheral Blood T Cells is Associated With Progressive Disease in Osteosarcoma Patients. FEBS Open Bio (2016) 6(8):807-15. doi: 10.1002/2211-5463.12079

64. Teng J, Guo X, Wang H. CCEPR is a Novel Clinical Biomarker for Prognosis and Regulates Cell Proliferation Through PCNA in Osteosarcoma. J Cell Biochem (2019) 120(8):12796-802. doi: 10.1002/jcb.28550

65. Wang Z, Luo C, Wang H, Yan X, Liu W, Meng Z. CEACAM6 is Associated With Osteosarcoma Metastasis and Facilitates Epithelial-Mesenchymal Transition in Osteosarcoma Cells. Onco Targets Ther (2018) 11:3159-66. doi: 10.2147/OTT.S161807

66. Savitskaya YA, Rico G, Linares L, Gonzalez R, Tellez R, Estrada E, et al. Circulating Natural Igm Antibodies Against Angiogenin in the Peripheral Blood Sera of Patients With Osteosarcoma as Candidate Biomarkers and Reporters of Tumorigenesis. Biomark Cancer (2010) 2:65-78. doi: 10.4137/ BIC.S6040

67. Bao HX, Bi Q, Han Y, Zhao C, Zou H. Potential Mechanisms Underlying CDK5 Related Osteosarcoma Progression. Expert Opin Ther Targets (2017) 21(5):455-60. doi: 10.1080/14728222.2017.1310194

68. Yu H, Yu J, Ren Y, Yang Y, Xiao X. Serum CEACAM1 Level is Associated With Diagnosis and Prognosis in Patients With Osteosarcoma. PloS One (2016) 11(4):e0153601. doi: 10.1371/journal.pone.0153601 
69. Sasaki H, Setoguchi T, Matsunoshita Y, Gao H, Hirotsu M, Komiya S. The KnockDown of Overexpressed EZH2 and BMI-1 Does Not Prevent Osteosarcoma Growth. Oncol Rep (2010) 23(3):677-84. doi: 10.3892/or_00000684

70. Righi A, Gambarotti M, Sbaraglia M, Sisto A, Ferrari S, Dei Tos AP, et al. P16 Expression as a Prognostic and Predictive Marker in High-Grade Localized Osteosarcoma of the Extremities: An Analysis of 357 Cases. Hum Pathol (2016) 58:15-23. doi: 10.1016/j.humpath.2016.07.023

71. Borys D, Canter RJ, Hoch B, Martinez SR, Tamurian RM, Murphy B, et al. P16 Expression Predicts Necrotic Response Among Patients With Osteosarcoma Receiving Neoadjuvant Chemotherapy. Hum Pathol (2012) 43(11):1948-54. doi: 10.1016/j.humpath.2012.02.003

72. Kikuta K, Tochigi N, Saito S, Shimoda T, Morioka H, Toyama Y, et al. Peroxiredoxin 2 as a Chemotherapy Responsiveness Biomarker Candidate in Osteosarcoma Revealed by Proteomics. Proteomics Clin Appl (2010) 4 (5):560-7. doi: 10.1002/prca.200900172

73. Li Y, Flores R, Yu A, Okcu MF, Murray J, Chintagumpala M, et al. Elevated Expression of CXC Chemokines in Pediatric Osteosarcoma Patients. Cancer (2011) 117(1):207-17. doi: 10.1002/cncr.25563

74. Trieb K, Gerth R, Windhager R, Grohs JG, Holzer G, Berger P, et al. Serum Antibodies Against the Heat Shock Protein 60 are Elevated in Patients With Osteosarcoma. Immunobiology (2000) 201(3-4):368-76. doi: 10.1016/s01712985(00)80091-1

75. Trieb K, Gerth R, Holzer G, Grohs JG, Berger P, Kotz R. Antibodies to Heat Shock Protein 90 in Osteosarcoma Patients Correlate With Response to Neoadjuvant Chemotherapy. Br J Cancer (2000) 82(1):85-7. doi: 10.1054/ bjoc. 1999.0881

76. Serra M, Scotlandi K, Manara MC, Maurici D, Benini S, Sarti M, et al. Analysis of P-Glycoprotein Expression in Osteosarcoma. Eur J Cancer (1995) 31a(12):1998-2002. doi: 10.1016/0959-8049(95)00335-5

77. Chan HS, Grogan TM, Haddad G, DeBoer G, Ling V. P-Glycoprotein Expression: Critical Determinant in the Response to Osteosarcoma Chemotherapy. J Natl Cancer Inst (1997) 89(22):1706-15. doi: 10.1093/ jnci/89.22.1706

78. Casiano CA, Mediavilla-Varela M, Tan EM. Tumor-Associated Antigen Arrays for the Serological Diagnosis of Cancer. Mol Cell Proteomics (2006) 5 (10):1745-59. doi: 10.1074/mcp.R600010-MCP200

79. Soo HL, Zhang JY, Chan E. Cloning and Characterization of a Novel 90 Kda'companion'auto-Antigen of P62 Overexpressed in Cancer. Oncogene (2002) 21(32):5006-15. doi: 10.1038/sj.onc.1205625

80. Zhu Q, Liu M, Dai LP, Ying X, Ye H, Zhou YS, et al. Using Immunoproteomics to Identify Tumor-Associated Antigens (Taas) as Biomarkers in Cancer Immunodiagnosis. Autoimmun Rev (2013) 12 (12):1123-8. doi: 10.1016/j.autrev.2013.06.015

81. Mian S, Ugurel S, Parkinson E, Schlenzka I, Dryden I, Lancashire L, et al. Serum Proteomic Fingerprinting Discriminates Between Clinical Stages and Predicts Disease Progression in Melanoma Patients. J Clin Oncol (2005) 23 (22):5088-93. doi: 10.1200/jco.2005.03.164

82. Petricoin EF, Ardekani AM, Hitt BA, Levine PJ, Fusaro VA, Steinberg SM, et al. Use of Proteomic Patterns in Serum to Identify Ovarian Cancer. Lancet (2002) 359(9306):572-7. doi: 10.1016/s0140-6736(02)07746-2

83. Shin BK, Wang H, Hanash S. Proteomics Approaches to Uncover the Repertoire of Circulating Biomarkers for Breast Cancer. J Mammary Gland Biol Neoplasia (2002) 7(4):407-13. doi: 10.1023/a:1024038132381

84. Canelle L, Bousquet J, Pionneau C, Deneux L, Imam-Sghiouar N, Caron M, et al. An Efficient Proteomics-Based Approach for the Screening of Autoantibodies. J Immunol Methods (2005) 299(1-2):77-89. doi: 10.1016/j.jim.2005.01.015

85. Zhang JY, Tan EM. Autoantibodies to Tumor-Associated Antigens as Diagnostic Biomarkers in Hepatocellular Carcinoma and Other Solid Tumors. Expert Rev Mol Diagn (2010) 10(3):321-8. doi: 10.1586/erm.10.12

86. Klade CS, Voss T, Krystek E, Ahorn H, Zatloukal K, Pummer K, et al. Identification of Tumor Antigens in Renal Cell Carcinoma by Serological Proteome Analysis. Proteomics (2001) 1(7):890-8. doi: 10.1002/1615-9861 (200107) 1:7<890::Aid-prot890>3.0.Co;2-z

87. Klade CS. Proteomics Approaches Towards Antigen Discovery and Vaccine Development. Curr Opin Mol Ther (2002) 4(3):216-23.

88. Looi KS, Nakayasu ES, Diaz RA, Tan EM, Almeida IC, Zhang JY. Using Proteomic Approach to Identify Tumor-Associated Antigens as Markers in
Hepatocellular Carcinoma. J Proteome Res (2008) 7(9):4004-12. doi: 10.1021/pr800273h

89. Zhang J, Wang K, Zhang J, Liu SS, Dai L, Zhang JY. Using Proteomic Approach to Identify Tumor-Associated Proteins as Biomarkers in Human Esophageal Squamous Cell Carcinoma. J Proteome Res (2011) 10(6):286372. doi: $10.1021 / \mathrm{pr} 200141 \mathrm{c}$

90. Peng B, Huang X, Nakayasu ES, Petersen JR, Qiu S, Almeida IC, et al. Using Immunoproteomics to Identify Alpha-Enolase as an Autoantigen in Liver Fibrosis. J Proteome Res (2013) 12(4):1789-96. doi: 10.1021/pr3011342

91. Cohen L, Walt DR. Single-Molecule Arrays for Protein and Nucleic Acid Analysis. Annu Rev Anal Chem (Palo Alto Calif) (2017) 10(1):345-63. doi: 10.1146/annurev-anchem-061516-045340

92. Chang L, Rissin DM, Fournier DR, Piech T, Patel PP, Wilson DH, et al. Single Molecule Enzyme-Linked Immunosorbent Assays: Theoretical Considerations. J Immunol Methods (2012) 378(1-2):102-15. doi: 10.1016/ j.jim.2012.02.011

93. Wu D, Katilius E, Olivas E, Dumont Milutinovic M, Walt DR. Incorporation of Slow Off-Rate Modified Aptamers Reagents in Single Molecule Array Assays for Cytokine Detection With Ultrahigh Sensitivity. Anal Chem (2016) 88(17):8385-9. doi: 10.1021/acs.analchem.6b02451

94. Rodero MP, Decalf J, Bondet V, Hunt D, Rice GI, Werneke S, et al. Detection of Interferon Alpha Protein Reveals Differential Levels and Cellular Sources in Disease. J Exp Med (2017) 214(5):1547-55. doi: 10.1084/jem.20161451

95. Koziol JA, Zhang JY, Casiano CA, Peng XX, Shi FD, Feng AC, et al. Recursive Partitioning as an Approach to Selection of Immune Markers for Tumor Diagnosis. Clin Cancer Res (2003) 9(14):5120-6.

96. Zhang JY, Casiano CA, Peng XX, Koziol JA, Chan EK, Tan EM. Enhancement of Antibody Detection in Cancer Using Panel of Recombinant Tumor-Associated Antigens. Cancer Epidemiol Biomarkers Prev (2003) 12(2):136-43.

97. Dai L, Ren P, Liu M, Imai H, Tan EM, Zhang JY. Using Immunomic Approach to Enhance Tumor-Associated Autoantibody Detection in Diagnosis of Hepatocellular Carcinoma. Clin Immunol (2014) 152(12):127-39. doi: 10.1016/j.clim.2014.03.007

98. Asemissen AM, Brossart P. Vaccination Strategies in Patients With Renal Cell Carcinoma. Cancer Immunol Immunother (2009) 58(7):1169-74. doi: 10.1007/s00262-009-0706-7

99. Pilla L, Rivoltini L, Patuzzo R, Marrari A, Valdagni R, Parmiani G. Multipeptide Vaccination in Cancer Patients. Expert Opin Biol Ther (2009) 9(8):1043-55. doi: 10.1517/14712590903085109

100. Schneble E, Clifton GT, Hale DF, Peoples GE. Peptide-Based Cancer Vaccine Strategies and Clinical Results. Methods Mol Biol (2016) 1403:797-817. doi: 10.1007/978-1-4939-3387-7_46

101. Bezu L, Kepp O, Cerrato G, Pol J, Fucikova J, Spisek R, et al. Trial Watch: Peptide-Based Vaccines in Anticancer Therapy. Oncoimmunology (2018) 7 (12):e1511506. doi: 10.1080/2162402x.2018.1511506

102. Gautam SK, Kumar S, Dam V, Ghersi D, Jain M, Batra SK. MUCIN-4 (MUC4) is a Novel Tumor Antigen in Pancreatic Cancer Immunotherapy. Semin Immunol (2020) 47:101391. doi: 10.1016/j.smim.2020.101391

103. Wang QT, Nie Y, Sun SN, Lin T, Han RJ, Jiang J, et al. Tumor-Associated Antigen-Based Personalized Dendritic Cell Vaccine in Solid Tumor Patients. Cancer Immunol Immunother (2020) 69(7):1375-87. doi: 10.1007/s00262020-02496-w

Conflict of Interest: The authors declare that the research was conducted in the absence of any commercial or financial relationships that could be construed as a potential conflict of interest.

The reviewer JS declared a shared affiliation, with no collaboration, with one of the authors $\mathrm{BQ}$ to the handling editor at the time of the review.

Copyright $\odot 2021 \mathrm{Li}$, Qin, Huang, Ma, Li, Li and Guo. This is an open-access article distributed under the terms of the Creative Commons Attribution License (CC BY). The use, distribution or reproduction in other forums is permitted, provided the original author(s) and the copyright owner(s) are credited and that the original publication in this journal is cited, in accordance with accepted academic practice. No use, distribution or reproduction is permitted which does not comply with these terms. 